\title{
Turn to Practice Within Working Life Studies
}

\author{
I Anders Buch' \\ Associate Professor, Aalborg University, Denmark
}

I Vibeke Andersen

Associate Professor, Aalborg University, Denmark

\section{Lars Klemsdal}

Associate Professor, University of Stavanger, Norway

\section{DOI}

\subsection{4/njwls.v5i3a.4830}

\begin{abstract}
hat does practice theory and practice-based studies have to offer working life studies? This is the seminal question this special issue poses. In seven articles, researchers with an affiliation to Nordic working life studies and with a background in practice theory illustrate and reflect on how practice theoretical approaches can help working life studies in better understanding work practices and the material, technological, economic, organizational, and societal conditions that shape and are shaped by these practices. In addition, this issue contains three reviews of recent practice theoretical volumes that strive to theorize (work) practices and assess the merits of practice theoretical perspectives.
\end{abstract}

\section{The general "turn to practice" in the social sciences}

The practice theoretical tradition has grown out of anthropology, sociology, geography, history, philosophy, and related academic disciplines that have an interest in understanding human action, agency, and social activities. Nowadays, an increasing number of scholars choose to focus on the day-to-day practices of actors in their studies of how human conduct is shaped by and is shaping society. This recent turn to practice can be traced back to growing dissatisfaction with social explanations that draws heavily on structuralist, individualistic, or mentalist conceptions of human activity. Sherry Ortner (1984) has argued "that a new key symbol of theoretical orientation is emerging, which may be labeled 'practice' or 'action' or 'praxis'. This is neither a theory nor a method in itself, but rather [...] a symbol, in the name of which a variety of theories and methods are being developed." Practice theoretical approaches thus covers a broad heterogeneous assembly of theoretical positions within the social sciences. Common for these are that they agree on shifting the focus of analysis from the individual actor, the isolated subject, bounded systems, and representations of knowledge, symbols, and ideational meanings

\footnotetext{
${ }^{1}$ E-mail: buch@learning.aau.dk
} 
to the practices we inevitably participate in when going about our daily business as social beings, whether at work or in our leisure time. Practice theoretical approaches thus gives priority to the study of embodied actions, emotions, things, technologies, interactions, encounters, performances, and actual use. On this very fundamental level, the practice theoretical tradition is guided by Wittgenstein's critique of representationalism, mentalism, and dualisms (cf. Wittgenstein, 1953)_ “meaning” should rather be understood as constituted by embodied practices.

The turn to "practice" can be identified in a number of academic disciplines. Philosophers like Theodore Schatzki (1996, 2002, 2010), Joseph Rouse (2007), Charles Taylor (1995), and sociologists like Andreas Reckwitz (2002a, 2002b) have sketched out the fundamental ontological and epistemological presumptions of practice theories in relation to agency, the social, and society, and described how practice theories draw on philosophical insights from mainly the late Wittgenstein and the younger Heidegger, but also significantly the early Giddens, Bourdieu, Butler, and the late Foucault. In organizational studies, social scientists like Wanda Orlikowski (2000, 2002), Silvia Gherardi (2006), Davide Nicolini (2013), and others have theorized and analyzed the role of technology within organizational development and change, and learning theorists like Paul Hager (2012), Joy Higgs (2012), Kemmis (Kemmis et al., 2014), Jean Lave (1988, 2011), Jean Lave and Etienne Wenger (1991), and Etienne Wenger (1998) have demonstrated how learning processes are best understood as transformations of and within practices. In another intellectual tradition, namely activity-theory, Yrgö Engeström (1999) and others have studied work practices and stressed the interplay with the material environment and the role of tools as essential features of human practices. The practice theoretical approaches have spread to other areas of research like consumption (Shove et al., 2012; Warde, 2005), sustainability studies (Cohen et al., 2013; Shove \& Spurling, 2013), professionalism (Fenwick \& Nerland, 2014), marketing, branding, accounting, and many more. In Science and Technology Studies (STS), practice theoretical approaches have appeared most notably in the works of Karin Knorr Cetina $(1985,1999)$ and Joseph Rouse $(1996,2002)$, but practice theoretical approaches are held in common with many STS approaches, for example, in the traditions of ethnomethodology (e.g., Suchman 2007), actor-network theory (Latour, 2005), and other posthumanist perspectives (e.g., Pickering, 1995). Soler et al. (2014) provide an overview on practice theory in STS. Several scientific journals have devoted special issues to the discussion of the new practice approaches within the social sciences (e.g., Organization 2000, The British Journal of Sociology 2002, and Human Affairs 2007) - thus, practice theoretical approaches have come to the fore and significantly influenced contemporary social science. Many scholars have observed this impact and described the increasing attention to social practices as a "practice turn" in social science (Schatzki et al., 2001) or a "bandwagon" of practicebased studies (Corradi et al., 2010). With this special issue, working life scholars have joined the "bandwagon"; they strike new notes and highlight how practices and the practice perspective can contribute to working life studies.

\section{What are practices?}

In trying to understand how practice theorists construe the notion of "Practice(s)," it is useful to reflect on Reckwitz's distinction between different notions of "practice" (2002a, 249):

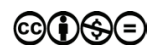


Practice (Praxis) in the singular represents merely an emphatic term to describe the whole of human action (in contrast to 'theory' and mere thinking). 'Practices' in the sense of the theory of social practices, however, is something else. A 'practice' (Praktik) is a routinized type of behavior which consists of several elements, interconnected to one another: forms of bodily activities, forms of mental activities, 'things' and their use, a background knowledge in the form of understanding, know-how, states of emotions and motivational knowledge.

Practice theorist study both "praxis" and "praktik," but it is essential to understand how "praxis" and "praktik" are related and how they differ. Schatzki (1996, pp. 89-90) has spelled out the different notions. One sense of practice (i.e., that of "praxis") denotes "performing an action or carrying out a practice." In this sense, individuals are carriers of practices because they perform specific patterns of actions and thus enact the practice. But practices can also be seen as coordinated entities (i.e., as "praktik"). In this sense, a practice is seen as a "temporally unfolding and spatially dispersed nexus of doings and sayings.” Schatzki characterize practices further:

Examples are cooking practices, voting practices, industrial practices, recreational practices, and correctional practices. To say that the doings and sayings forming a practice constitute a nexus is to say that they are linked in certain ways. Three major avenues of linkage are involved: 1) through understandings, for example, of what to say and do; 2) through explicit rules, principles, precepts and instructions; and 3) through what I will call 'teleoaffective' structures embracing ends, projects, tasks, purposes, beliefs, emotions and moods. (1996, 89)

In this latter sense of practices, it is an essential claim of practice theory that the performances of individuals are linked and interconnected in specific ways that form durable nexuses of actions. The configurations of the actions-doings and sayings-can endure in time and space and thus "carry" constellations of actions. It is important to notice that practices are not social structures that steer actions-on the contrary, individual actions contribute to the (de)stabilization of patterns of actions by enacting the patterns or deviating from the patterns of actions.

It is important to make yet another distinction in relation to types of practices. As we act, we constantly engage in different practices. Some of them are very common and appear in many (different) situations. "Calculating" is an example of such an activity. It might be performed by individuals in mundane settings-for example, in supermarkets where costumers are shopping for "best buys" (Lave, 1988)—or "calculating" might be performed by highly specialized particle physicist at work in esoteric settings (Traweek, 1988). What unites both of these instances of human performances into a common practice could roughly be described as the individuals' ability to manipulate numbers, figures, symbols, and so on according to specific rules-say those of multiplication, division, subtraction, and addition. A common understanding of what it means to "calculate" holds the constituent actions together, although other circumstances-including the ends, purposes, and beliefs of the actors-might vary significantly. These kinds of weakly linked activities Schatzki calls dispersed practice $(1996,91)$. Other sorts of more strongly linked activities can be characterized as integrative practices (Schatzki, 1996, $98 \mathrm{ff}$.). Individuals engaging in integrative practices do not only share specific practical 
understandings about how to "go on" in certain respects (e.g., to calculate), but they also often abide to specific explicit rules, regulations, and instructions of a domain, and they might also be united in upholding common perspectives, ends, tasks, projects, beliefs, and emotions. This is the case for many professional practices and practices taking place in work settings.

\section{Researching practices in working life}

What can a turn to practice within working life studies as of today mean? As it becomes clear from the above exposition, what has been called a practice turn within social science is fed by a long history of attention to the importance of focusing on human practices in order to understand how human activity as well as societies are constituted (cf. Eikeland, 2008), also for the interdisciplinary field of working life studies. For instance, there is a strong tradition within the so-called Chicago school of sociology, in focusing on practices when studying work and working life (Strauss, 1993). In the Nordic countries, there has also been a strong tradition for focusing on practice when studying working life, stemming from the sociotechnical tradition (Thorsrud \& Emery, 1976; Hvid et al., 2011), to the so-called Scandinavian institutionalist studies of implementation, management concepts, and so on (Røvik, 2007). So, how can we make sense of a recent turn to practice within working life studies?

The key lies in the meaning of the concept or notion of practice. The turn to practice we talk about refers to a conceptual shift that, for instance, can be characterized as a shift from an entirely humanist conception of practice to positions that recognize the distributed and shifting nature of agencies, as Silvia Gerhardi (2015) and Barbara Czarniawska (2015) do in their respective contributions in this issue. This is a shift that has been long time coming, as is demonstrated by the above expositions, but that is particularly associated with the publication of an anthology in 2001, edited by Theodore Schatzki et al. (2001).

Gherardi (2015) outline the assumptions of a post-humanist practice theory, which entails a shift in seeing the individual subject as the center and source of meaningful activity, to seeing social practices as the "sites" wherein individual subjects participate with their abilities together with (entangled with) technology, sociomateriality, and knowledge. Other practice theoretical accounts, drawing mainly on the framework of Theodore Schatzki's, like Buch and Andersen's contribution, also recognize the importance of material arrangements for analyzing work practices, although these accounts do not align with post-humanism. The word practice is picked out of the set of synonyms for activities as daily language usually put it in, and is given a distinct ontological and epistemological meaning, referring to ways things are done. We thus do not primarily practice our work. Rather at work, we participate in practices, contribute to enacting them and innovating them, at the same time as it is through being able to participate in these practices that we know what to do in particular situations-know how to do things with our hands or with technology, as well as we know or learn who we are as we participate in the particular practice.

Further, for instance, within the Scandinavian critical tradition for interventionist and action research approaches to research and development of working life, we can trace a turn to practice. Starting from normative sociotechnical experimentation with new forms of organizing during the 1960, this tradition took a so-called dialogical turn, 
which resulted in at least one distinct practice-oriented avenue for research into working life issues by becoming "researchers as native apprentices in local practices," examining their own practices as researchers at the same time (cf. Eikeland, 2006). This is an avenue that is followed up in this issue by Wadel (2015). In modern practice, theoretical frameworks critical intervensionist action research is proposed fused with practice theoretical categories by Stephen Kemmis (2008) and Kemmis et al. (2014b).

Thus, although many differences can indeed be found (cf. Nicolini \& Monteiro, 2016), there seems to be an agreement within practice theoretical positions that human activities should be studied by focusing on activities and doings, including what we do with words. But further than that, a common denominator of the various modern practice approaches seems to be that most of what we do makes sense by the lights of the social practices our actions are part of. "Practices"-not symbols, meanings, or structures-are seen as the fundamental "carriers" of social phenomena.

The practice theoretical approach, then, in many ways sets a new agenda for our understanding of social phenomena, social order, how social phenomena relates to materiality and how change comes about. Its refusal to frame social phenomena and human activity in the idiom of the Cartesian epistemology of "opposites" has fundamental methodological consequences. The practice theoretical approach construes social phenomena and human activity in a thoroughly relational ontology that refuse to work within a binary framework of dualisms. Refusing to accept absolute demarcations between agency/structure, inside/outside, mind/body, rationality/emotions, theory/practice, nature/society, and so on as the point of departure for explanations, the approach instead seeks to trace how these dualisms are instantiated and reenacted in social practices. In this perspective, practices—understood as the realm of social performances and actions (the doings and sayings of actors)—should be the object of critical analysis and the researcher should not presuppose but instead try to explain how they are instituted in a social realm in the first place. Honoring this imperative means that it is not legitimate to presuppose "natural" or "absolute" distinctions between practical and theoretical work, technical and social elements, professionalism as opposed to craftsmanship, hard and soft skills, and so on. In fact, these dichotomies should be perceived as the explanandum of critical scholarly analysis. The study of practices in working life situations should thus seek to understand how the social categories and distinctions are constructed, reenacted, and naturalized within a social realm. Social action and the performativity of the actors in the social realm is thus the object of investigation, analysis, and explanation in the practice theoretical approach. Although of immense importance, this general ontological statement of the practice theoretical approach does not give much methodological and practical guidance to the study of work practices. We need to consider in more detail how to approach and frame the study of human activity conceived as a seamless continuum of performances-doings and sayings. The social ontology outlined above must be supplemented by methodological considerations. If human activity and the social should be conceived in thoroughly relational terms and if social reality should be conceived of as nexuses of practice-order bundles that are propelled and morphed by human and nonhuman doings-how are we to study this extremely complex, relational, and intertwined mesh that transpires and extends almost indefinitely in space and time? Where should our research start and end and how should it be delimited in order to provide sound analysis and explanations of working life? This very much depends on the specific purposes and interests of the researcher engaged 
with practice theoretical approaches. Reflecting on methodological approaches taken by practice theoreticians Nicolini and Monteiro (2016) points to four different avenues: first, a situational approach that focuses on concerted accomplishments of (diverse) practices within rather well defined scenes of activity, for example, studies of work place settings; second, genealogical approaches that focus on (particular) discrete practices, how they evolve, intersect with other practices, dissolve, mutate, and so on. This approach might be useful for working life researchers with a specific interest in the study of specific practices of professionalism, craftsmanship, and so on. Third, configurational approaches that focus on understanding how practices hang together and integrate in larger constellations or assemblages in wider space-time regions. This approach could be appealing for working life researchers who are interested in understanding contemporary working life phenomena-say how "psychological burnout" is dealt with in modern work environments. Finally, fourth, a dialectical approach investigates "the co-evolution, conflict, interference of two or more practices." This latter perspective could be of relevance to working life researchers, with a specific research interest in investigating power relations and processes of marginalization and oppression within working life.

In this special issue addressing a turn to practice within working life studies, we are presenting a variety of papers from empirical studies of how practices unfold and frame particular work situations to papers addressing foundational issues related to practice theory and practice-oriented approaches to the study of working life. Let us briefly introduce the articles of this special issue.

In "How the Turn to Practice may contribute to Working Life studies," Silvia Gherardi reflects on the potential contribution that the turn to practice may offer to working life research. Gherardi elaborates how a radical turn to practice will enhance our understanding and ability to analyze how the different elements and dimensions of working situations are brought together, and become constituted, defined, made specifically sensible, and meaningful as well as instrumentally effective in action. Seeing practice as the process where all these elements and dimensions are activated, brought to life, or actualized in an Aristotelian sense makes us aware how knowing and acting at work is connected, not only intimately but also inwardly. We know by acting, as well as we act knowingly. Our relationship with the material context of our working situations is not only constituted by the combination of material possibilities/potentialities and individual abilities to use or explore these possibilities, but primarily by the practices that surround or embody the material/technological and the human abilities (like water), by giving both materiality and ability a general meaning. In other words, from this perspective, we are invited to see how our abilities are nothing without the materiality at hand as well as the situations through which they are practiced. And it is through our practicing, the abilities and materialities become really defined, particularly constituted. As Gherardi points out: Practice is a way of doing things, it is also a way of knowing what to do, it is a way of sensing what is appropriate as well as effective. Practice is a medium that exists between us, that we participate in developing every day we act by the lights of our practices in specific situations.

The article "Fire and Water combined: Understanding the relevance of working life studies through a concept of practical activity" written by Räsänen is an attempt at offering a "kettle-like" vehicle for bringing together practice-theoretical concepts and vocational training, where fire and water are metaphors for practice and theory. The kettle is a concept of practical activity and the question the article wants to answer is:

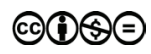


in what senses a study of work can be practically relevant to those who are doing the work being studied?

In the article, the concept of practice is presented with usability both in the case of research work and other forms of work, and usability to individual practitioners. The concept has emerged from different studies made by the author and a group of colleagues since the early 1990s and gradually influenced by the tradition of practice theory. The concept of practical activity invites researchers and practitioners to make inquiries in different aspects of work (tactics, politics, morals, subjects). A four-fold frame for articulating or describing any form of practice is presented in a table. The key idea is that the practitioner repeatedly encounters and has to negotiate on four basic issues: how to do, what to do, why to do, and who to do, assuming that these four issues in one way or another become resolved in any practice.

In order to explicate the use of the concept, research work is presented as a practical activity. The article concludes that we need a well-rounded concept of practice if we want to understand the possibilities and difficulties in making research that practitioners find relevant. The presented concept of practical activity provides a way of approaching this need, with illustrations from academic work. Still, a lot is to be done in making practice-based studies and practice-theoretical traditions practically relevant.

The article "Participatory work-along as a prentice-a qualitative research tool in studying organizations and work practices" by Wadel discusses which possibilities an apprentice role can offer to ethnographic fieldwork in work organizations. Being an apprentice puts the researcher in a unique position when it comes to learning from informants in the field, the article argues, given possibilities to perform work activities together with people in the field. In the article, it is called walk-along inspired from Kusenbach's work. To illustrate this, the article presents a fieldwork conducted within the public care system for elderly people in a Norwegian and a Swedish municipality, based on the researchers own fieldwork. The role of the apprentice refers to principles of "learning by doing" and a dynamic learning relationship based on full sharing, turning the apprentice into a master and learning being embedded in a social practice. Furthermore, it is an approach that emphasizes the apprentice's participation in a community of practice, where the community of practice is seen as the key factor in the learning process. Wadel stress that although the term apprentice is associated with training within professions, it can be used more generally-for instance as a research tool, where the researcher has the role of the apprentice.

There are several challenges and limitations related to work-along research as an apprentice. For instance, it is time-consuming and personally tiring to invest oneself as an apprentice, leaving no room for rest and reflections during the work time. Furthermore, it includes some ethical aspects related to the close relations to the people in the field. Being a researcher, the relations established had the purpose of producing research about care systems for elderly people, and not due to an ambition of caring for elderly people. Finally, there might occur problems regarding keeping distance to the field and not "going native," when research and being an apprentice is intertwined.

Through a practice theoretical lens, Anders Buch and Vibeke Andersen are analyzing attempts at changing the cooperative practices within two engineering consultancy firms through implementing conceptions of Team work. They find that the original conception of teamwork as formulated by the HR-departments was gradually dissolved by the ecology of established practices that surrounded the work situations of the practitioners. 
Through long-term ethnographic studies among the two groups of engineers on site, following their daily work, attending meetings, and so on, they explore in detail how the ambitions of new team organizing are interveawing and partly clashing with other contingencies, manifested through a variety of practices that comes together and prefigure the specific work situations the practitioners encounter, conditioning and shaping the possibilities of enacting the new team concept.

With the categories of Nicolini and Moteiro (2016), the study by Buch and Andersens can be categorized as a configurational approach to practice studies. They demonstrate how a practice approach is able to capture the broader organizational dynamics that form the context where implementation and planned change attempts are shaped and how "teamwork" is enacted in organizational practices influenced by the wider practice ecologies. The attention toward practices makes it possible to both map the complexity and the interactivity between the contingencies that prefigure the daily work situations of the engineers and demonstrate how social order is (re)produced.

In the article, "Multiple Forms of Professional Agency for (non)crafting of Work Practices in a Hospital Organization," Collin et al. are exploring how professional agency is manifested and unfolding among a group of physicians, nurses, and secretaries employed at an emergency unit in a Finnish hospital. The article analyses audio and video recordings from group sessions and plenary sessions at a workshop addressing possible innovations in work practices, particularly in order to improve inter-professional cooperation in the practitioners' daily work. They identify five different modes of agency at work during the group sessions, named transformative, responsive, relational, and resisting forms of agency. Further, they explore how professional positions defined by the positional hierarchy at the hospital are framing the variation of the particular modes of agency that is emphasized in the different settings, whether the groups are homogeneously or heterogeneously composed. The article builds on and expands theories of cultural activity theory. It contributes with a nuanced notion of how professional agency is at play both as a restrictive/enhancing force in processes of development and learning of new work practices as well as of interprofessional integration, among work organizations employing a variety of professions. The approach is typical of a situational character, studying the unfolding of practices within a limited timeframe, in this case practices of generating new ideas for improved working practices at an emergency unit in a hospital.

In the article titled "After Practice. A Personal Reflection," Barbara Czarniawska is reflecting on the turn to practice in 2001, relating this to her own field, management studies, and her own experiences as a management scholar trying to do something good for the society. This perspective on her own practice is inspired by Alasdair MacIntyre's conceptions of practice as striving for excellence. As Czarniawska writes, practices must be good, or striving toward achieving the good. When this generic definition is established, then the next question is what a turn to practice should mean for a management scholar and thus a theoretician? Is a turn to practice a turn away from theory? And further, are theory and practice two distinctive realms that only connect indirectly, as irritations, in Niklas Luhmanns terms and so on? Or is it possible to establish a middle ground of the practice of theory and the practice of practice in the sense that Donald Schön suggests when he conceptualizes the movement of the expert practitioner from being a reflecting practitioner, reflecting in action, to becoming a reflexive practitioner, able to reflect on the reflection in action. Thus, in other words, how might the management scholar contribute and do good in society in her practice, as a contributor to the

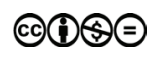


reflections on the reflecting in action that presumably drives the practitioners' actions every day. Or as an irritant, able to disturb hopefully in productive ways, the reflection on action in everyday activities. It seems that she concludes with "yes please, I take both" as she finds the legitimate role of the theoretician on practice, the academic student of management, and organization practices as a critic that in detailed ways can evaluate the performances of the practitioners, at the same time as placing it within a historical perspective. As she concludes, such a stance requires a closeness to practice to get hold of the details, at the same time as keeping a distance in order to be able to problematize "rather than theorizing it still further." This suggestion can maybe also work for establishing a legitimate function of the working life researcher: how working life researcher may contribute with good to society.

Finally, three book reviews of recently published books on practice theory are presented, all reviewed by scholars well situated within practice-oriented approaches: Anders Buch reviews Davide Nicolinis Practice Theory, Work, and Organization. An Introduction; Iben Jensen reviews How to Conduct a Practice-Based Study. Problems and Methods, by Silvia Gherardi; and Stine Willum Adrian reviews the textbook from Oxford University Press How Matter Matters. Objects, Artifacts, and Materiality in Organization Studies, edited by Paul R. Carlile, Davide Nicolini, Ann Langley, and Hardimos Tsoukas. All three works can be considered central readings for scholars interested in entering or enhancing their situation within the scholarly field of practiceoriented studies of work and organizations.

\section{References}

Buch, A. \& Andersen, V. (2015) Team and project work in engineering practices, Nordic Journal of Working Life Studies, 5(3a).

Cohen et al. (2013) Innovation in Sustainable Consumption: New Economics, Social-Technical Transitions and Social Practices, London, Edward Elgar Publishing.

Collin, K., Paloniemi, S. \& Wähäsantanen, K. (2015) Multiple forms of agency for (non)crafting of work practices in hospital organization, Nordic Journal of Working Life Studies, $5(3 a)$.

Corradi et al. (2010) Through the practice lens: where is the bandwagon of practice-studies heading?, Management Learning, 41(3), 265-283.

Czarniawska, B. (2015) After practice. A personal reflection, Nordic Journal of Working Life Studies, 5(3a).

Eikeland, O. (2006) "The validity of action research—validity in action research" in Action and Interactive Research. K. Aagaard Nielsen and L. Svensson (eds). Maastricht: Shaker. pp. 193-240.

Eikeland, O. (2008) The Ways of Aristotle: Aristotelian Phronesis, Aristotelian Philosophy of Dialogue, and Action Research. Bern: Peter Lang.

Gherardi, S. (2015) How the turn to practice may contribute to working life studies, Nordic Journal of Working Life Studies, 5(3a).

Engeström, Y. (1999) Activity Theory and Individual and Social Transformation. Cambridge: Cambridge University Press.

Engeström et al. (eds.): Perspectives on Activity Theory, Cambridge: Cambridge University Press.

Fenwick, T. \& Nerland, M. (eds.) (2014) Reconceptualising Professional Learning. Sociomaterial Knowledges, Practices and Responsibilities, London: Routledge. 
Gherardi, S. (2006) Organizational Knowledge: The Texture of Workplace Learning, Oxford: Blackwell.

Hager, P. et al. (eds.) (2012) Practice, Learning and Change. Theory Perspectives on Professional Learning, Dordrecht: Springer.

Higgs, A. et al. (eds.) (2012) Practice-Based Education. Perspectives and Strategies, Dordrecht: Sense Publishers.

Hvid, H. et al (2011) Nordic working life research—continuity and renewal. Nordic Journal of Working Life Studies, 1(1), 3-21.

Kemmis, S. (2008): Critical theory and participatory action research, in Reason, P. \& Bradbury, H. (eds.): Handbook of Action Research Participative Inquiry and Practice, London: Sage Publications, 2nd edition. pp. 21-138.

Kemmis, S., Wilkinson, J., Edwards-Groves, C., Hardy, I., Grootenboer, P. \& Bristol, L. (2014a) Changing Practices, Changing Education, Dordrecht: Springer.

Kemmis, S., McTaggart, R. \& Nixon, R. (2014b): The Action Research Planner. Doing Critical Participatory Action Research, Dordrecht: Springer.

Knorr Cetina, K. (1985) The Manufacture of Knowledge: Essays on Constructivist and Contextual Nature of Science, New York: Pergamon.

Knorr Cetina, K. (1999) Epistemic Cultures: How the Sciences Makes Knowledge, Boston: Harvard University Press.

Latour, B. (2005) Reassembling the Social. An Introduction to Actor-Network-Theory, Oxford: OUP.

Lave, J. (1988) Cognition in Practice, Cambridge: Cambridge University Press.

Lave, J. (2011) Apprenticeship in Critical Ethnographic Practice, Chicago: Chicago University Press.

Lave, J. \& Wenger, E. (1991) Situated Learning. Legitimate Peripheral Participation, Cambridge: Cambridge University Press.

Nicolini, D. (2013) Practice Theory, Work, \& Organization. An Introduction, Oxford: Oxford University Press.

Nicolini, D. \& Moteiro, P. (2016) The practice approach: for a praxeology of organisational and management studies, in Tsoukas, H. \& Langley, A. (eds.) The SAGE Handbook of Process Organization Studies, London: SAGE.

Orlikowski, W. (2000) Using technology and constituting structures, Organization Science, 11(4), 404-428.

Orlikowski, W. (2002) Knowing in practice: enacting a collective capability in distributed organizing, Organization Science, 13(3), 249-273.

Ortner, S. (1984) Theory in anthroplogy since the sixties, Comparative Studies of Society and History, 26(1), 126-166.

Pickering, A. (1995) The Mangle of Practice. Time, Agency and Science, Chicago: Chicago University Press.

Reckwitz, A. (2002a) Toward a theory of social practices. A development in culturalist theorizing, European Journal of Social Theory, 5(2), 243-263.

Reckwitz, A. (2002b) The status of the "material" in theories of culture: from "social structure" to "artefact", Journal for the Theory of Social Behaviour, 32(2), 195-217.

Rouse, J. (1996) Engaging Science. How to Understand its Practices Philosophically, New York: Cornell University Press.

Rouse, J. (2002) How Scientific Practices Matter. Reclaiming Philosophical Naturalism, Chicago: Chicago University Press.

Rouse, J. (2007) Practice Theory, Division I Faculty Publications. Paper 43. Available at: http://wesscholar.wesleyan.edu/div1facpubs/43 (Accessed July 2015).

Røvik, K. A (2007) Trender og translasjoner, Oslo: Universitetsforlaget. 
Schatzki, T. (1996) Social Practices: A Wittgensteinian Approach to Human Activity and the Social, Cambridge: Cambridge University Press.

Schatzki, T. (2002) The Site of the Social. A Philosophical Account of the Constitution of Social Life and Change, New York: Penn State Press.

Schatzki, T. (2010) The Timespace of Human Activity. On Performance, Society and History as Indeterminate Teleological Events, Lexington: Lexington Books.

Schatzki, T. et al. (eds.) (2001) The Practice Turn in Contemporary Theory, London: Routledge.

Shove, E. et al. (2012) The Dynamics of Social Practice. Everyday Life and How it Changes, London: SAGE Publications.

Shove, E. \& Spurling, N. (2013) Sustainable Practices: Social Theory and Climate Change, London: Routledge.

Soler, L. et al. (2014) Introduction, in Soler, L. et al. (eds.), Science After the Practice Turn in the Philosophy, History, and Social Studies of Science, pp. 1-43. New York: Routledge.

Strauss, A. (1993) Continual Permutation of Action. New York: Aldine de Gruyter.

Suchman, L. (2007) Human-Machine Reconfigurations. Plans and Situated Actions, 2nd edition, Cambridge: Cambridge University Press.

Taylor, C. (1995) Lichtung or Lebensform: parallels between Heidegger and Wittgenstein, in Taylor, C. Philosophical Arguments, Boston: Harvard University Press. pp. 61-78.

Thorsrud, E. \& F. Emery (1976) Democracy at work: the report of the Norwegian industrial democracy program. Leiden: Martinus Nijhoff Social Sciences Division.

Traweek, S. (1988) Beamtimes and Lifetimes. The World of High Energy Physicists, Boston: Harvard University Press.

Warde, A. (2005) Consumption and theories of practice, Journal of Consumer Culture, 5, 131-153.

Wenger, E. (1998) Communities of Practice. Learning, Meaning, and Identity, Cambridge: Cambridge University Press.

Wittgenstein, L. (1953) Philosophical Investigations, Oxford: Basil Blackwell. 